Voix et Images

voixetimages

\title{
Comment brillent encore les Grands Soleils
}

\section{Bernard Andrès}

Volume 3, numéro 1, septembre 1977

Nicole Brossard

URI : https://id.erudit.org/iderudit/200094ar

DOI : https://doi.org/10.7202/200094ar

Aller au sommaire du numéro

Éditeur(s)

Les Presses de l'Université du Québec

ISSN

0318-9201 (imprimé)

1705-933X (numérique)

Découvrir la revue

Citer cet article

Andrès, B. (1977). Comment brillent encore les Grands Soleils. Voix et Images, 3(1), 147-149. https://doi.org/10.7202/200094ar d'utilisation que vous pouvez consulter en ligne.

https://apropos.erudit.org/fr/usagers/politique-dutilisation/ 


\section{Comment brillent encore les Grands Soleils}

Bien que la plupart des compagnies misent toujours sur le répertoire international pour établir le fond de leur programmation, la saison 19761977 aura quand même permis au spectateur métropolitain du théâtre institutionnel de voir pu de revoir une douzaine de pièces québécoises ${ }^{1}$. Un bref survol des principaux spectacles s'établirait ainsi:

\section{SAISON 1976-1977}

\section{Créations}

Coup de sang, de J. Daigle (TNM)

Le Réformiste, de M. Dubé (TNM)

Gapi, d'A. Maillet (TRV)

Damnée Manon, sacrée Sandra de M. Tremblay (Quat'sous)
Reprises

Inespérée, Inattendu, de R. Ducharme (NCT) Évangéline Deusse, d'A. Maillet (TRV)

Médium saignant, de F. Loranger (CJD)

J'peux pas rester, on m'attend d'Yves Sauvageau (T. d'A.)

Les Faux Brillants, de F.-G. Marchand (T. d'A.)

Le Temps d'une vie, de R. Lepage (Trident)

Le Cid maghané, de R. Ducharme (Trident)

Les Grands Soleils, de J. Ferron (PJML)

Un double déséquilibre est à noter: par rapport au répertoire international et par rapport à la création québécoise. Le ministère des Affaires culturelles semble décidé à intervenir dans ce ciomaine en imposant aux grands théâtres subventionnés un minimum d'une création québécoise par $a^{2}$. II a été question ailleurs des quatre créations mentionnées plus haut, parmi lesquelles se détache Damnée Manon, Sacrée Sandra, dernière pièce d'après l'auteur, du «cycle des Belles-Sœurs». Parmi les reprises dont j'ai aussi traité dans Jeu et dans le Jour, je m'arrêterai ici aux Grands Soleils de Jacques Ferron. Cette pièce, créée en 1968 au TNM par Albert Millaire, avait attendu dix ans pour accéder aux planches. Les Grands Soleils présentent l'intérêt de poser de façon aiguë les pro- 
blèmes de l'adaptation scénique et du rapport au public. On se rappelle la réaction de ce dernier, aussi déconcerté quelques mois avant les Belles Sœurs par la destructuration temporelle et formelle de la pièce, que par sa thématique nationaliste.

Avec le temps on est surtout sensible aujourd'hui au problème de l'adaptation à la scène du texte éminemment littéraire de Ferron. Luimême ne reconnaissait-il pas à l'époque qu'il faut «être fou pour publier

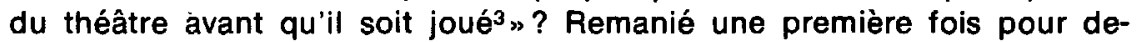
venir en 1968 un "cérémonial " théâtral, le texte le fut à nouveau cet été au Théâtre du Bois de Coulonge, dans une production de J.-M. Lemieux ${ }^{4}$. Sept mois s'étaient écoulés depuis le 15 novembre 1976 et l'on tenait à souligner le fait. Toute la production s'en ressentit. Alors que le texte original, tout comme la version de 1968 , se présentait comme une vaste réflexion sur le nationalisme à partir des troubles de 1837 , la dernière production de la pièce se trouve plutôt orientée vers une consécration de la figure mythique de Papineau. Tout se joue autour de la scène liminaire, dite “d'exorcisme préalable». J.-M. Lemieux l'a repoussée à la toute fin du spectacle. Placée normalement en tête de la pièce, cette scène où chacun s'investit de l'éloquence révolutionnaire de Papineau, était subséquemment pondérée par le reste de la pièce dont la portée critique n'épargnait aucun acteur du drame national. Pas plus Chénier que Mithridate, non plus que le curé de Saint-Eustache, Félix Poutré ou le Canadienerrant, ne sortaient indemnes de l'ironie ferronnienne. Par les feux croisés de points de vue contradictoires, ces personnages battaient en brèche la (?) vérité historique. Mouvante, multiple (les Grands Soleils), celle-ci défiait l'esprit critique du spectateur qui, comme dans le théâtre épique de Brecht (à qui on a comparé Ferron), devait se faire une opinion. Dans la nouvelle production, on a plutôt l'impression que la Vérité se livre, exacte et univoque, à la fin du spectacle 5 .

Était-ce le Chénier du premier acte, sûr de lui et de sa mission? Ou celui du deuxième, interrogeant Mithridate sur son destin? Est-ce Félix Poutré, l'homme à deux faces, le traître à la Patrie, ou le simple habitant qui protège ses biens en pressentant la trahison d'une petitebourgeoisie éloquente et prompte à l'exil? Est-ce le Canadien errant attachant et nostalgique, ou le "mercenaire" que "la vie intéresse" en Corée comme à Chypre? Seul Sauvageau «l'immémorial, celui qu'on a dépouillé de tout ", seul le Sauvage sortait indemne de ce panorama critique dans la version de 1968. Avec Mithridate, il avait le mot de la fin: «je remonte mes grands soleils aux quatre coins du pays». Par la permutation de la scène d'exorcisme, les Grands Soleils (1977) se clôturent dans une allégresse un peu de circonstance, chacun se saluant du nom de Papineau...

Par rapport aux autres modifications apportées par J.-M. Lemieux en accord avec J. Ferron ${ }^{6}$, cette redistribution de la séquence liminaire 
apporte un changement majeur à la configuration et à l'esprit de la pièce. Les Grands Soleils, c'est une pièce maîtresse d'il y a dix ans (voire vingt ans), dont l'impact fut certain à l'époque. Elle garde encore toute son efficacité, telle quelle, à condition de la resituer mentalement au lendemain du centenaire de la Confédération. Mais trop vouloir réactualiser la pièce, c'est encourir le danger de figer le 15 novembre dans la perspective des "belles catastrophes de 1837 dont Saint-Eustache a été l'apothéose" (Aquin). La pièce de 1977 reste un spectacle parfaitement monté et servi par l'équipe du Bois de Coulonge avec tout le dynamisme et le sens du jeu voulus.

Pour être plus immédiatement efficace (lancement coïncidant avec la première fête légale de la Saint-Jean), le “cérémonial» perd de sa portée critique en ramenant trop aisément la lutte politique actuelle au nationalisme d'hier... ou d'avant-hier.

\section{Bernard Andrès}

1. Pour ce qui est du jeune théâtre cuvrant presque exclusivement dans le domaine québécois, on se reportera à la revue Jeune Théatre, de l'AQJT, ainsi qu'aux chroniques de Jeu (nos 4 et 5) ef du Jour-hebdo.

2. Voir à ce sujet mes chroniques dans le Jour du 3 et du 10 juin 1977.

3. Cf. M. Dassylva, in la Presse du 29 avril 1968.

4. De tin mai à début septembre, à Sillery, dans un nouveau théâtre d'été. Mise en scène de J.-M. Lemieux (dans le rôle de Chénier), avec Jean Guy (à qui je dois le texte de travail de cette production et qui jouait Mithridate), Marie Tiffo (Élisabeth), René Massicotte (le Curé), Michel Daigle (Félix Poutré), André Cartier (François Poutré) et Denis Mercier (Sauvageau).

5. Sur "la nature fondamentalement critique de la théâtralité " chez Ferron, voir l'étude de J.-M. Paquette: "J. Ferron ou le drame de la théâtralité", in tome $V$ des Archives des lettres canadiennes, Montréal, Fides, 1976, p. 581-596.

6. Rappel du 15 novembre et coupures d'autres rappels historiques superflus déjà signalés par $L$. Mailhơ dans: "J. Ferron: de l'amour incertain à la patrie possible», in le Théatre québécois, en collaboration avec J.-Cléo Godin, Montréal, $\mathrm{HMH}, 1973$, p. 163. 